\title{
Volcanology of Tuzo pipe (Gahcho Kué cluster) - root-diatreme processes re-interpreted
}

\author{
I. Seghedi $^{1,2} *$, D. Maicher ${ }^{1}$, S. Kurszlaukis ${ }^{1}$ \\ ${ }^{1}$ De Beers Canada Exploration Inc., Suite 300, 65 Overlea Blvd, Toronto, ON, Canada, M4H 1P1 \\ ${ }^{2}$ Institute of Geodynamics, 19-21, Jean-Luis Calderon str., Bucharest 020032, Romania. \\ * email address: seghedi@geodin.ro
}

The Middle Cambrian ( 540 Ma) Gahcho Kué Kimberlite Field is situated about 275km ENE of Yellowknife, NWT, Canada. The Field is emplaced into 2.6Ga Archaean granitic rocks of the Yellowknife Supergroup. Four larger kimberlite bodies (5034, Tesla, Tuzo, and Hearne) as well as a number of smaller pipes and associated sheets occur in the field controlled by WNW-ESE trending faults crossed by NE-SW faults (Hetman et al., 2004).

In plan view Tuzo pipe has a circular outline at surface with an area of ca. 1.3 ha and widens towards depth (ca. 3.3 ha at $354 \mathrm{~m}$ below lake level). In winter 2007 Tuzo was drilled in a 35m-spacing grid of 26 vertical HQ drill cores (63mm diameter) to a depth of 300 or $400 \mathrm{~m}$. This study presents our volcanological key observations and suggests a new emplacement mechanism, which varies from the concept of the transition zone representing a "frozen" degassing front of a single phase of intrusive kimberlite emplacement (Hetman et al., 2004).

The pipe infill consists of several types of coherent and fragmental kimberlite facies. While coherent or apparent coherent (possibly welded) kimberlite phases dominate at depth, the central and shallower portions of the pipe are comprised of fragmental kimberlite varieties, which are texturally classified as Tuffisitic Kimberlites (TK). Several transitional kimberlite facies are recognized, which usually have gradual contacts to the adjacent kimberlite units; sharp contacts, most of which are subvertical and sometimes marked by cmsize serpentine veins, have also been observed (Fig. 1).

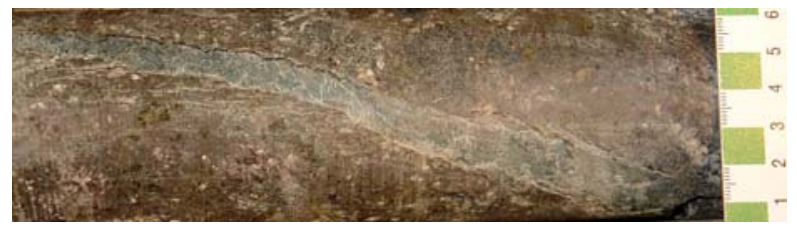

Fig.1. Sharp subvertical contact between two transitional TK facies marked by a serpentine veinlet.
The definition and extent of the geological units is complex, and a vertical expansion seems to dominate generally over a significant lateral extension. Although coherent Hypabyssal Kimberlite (HK, Fig.2) and transitional coherent kimberlite (HKt, Fig.4) dominate at depth, some occur also at shallow levels. They either represent late dikes, possibly agglutinated particles (HKt, Fig.3), or individual coherent magma particles (CMP, Fig. 4).

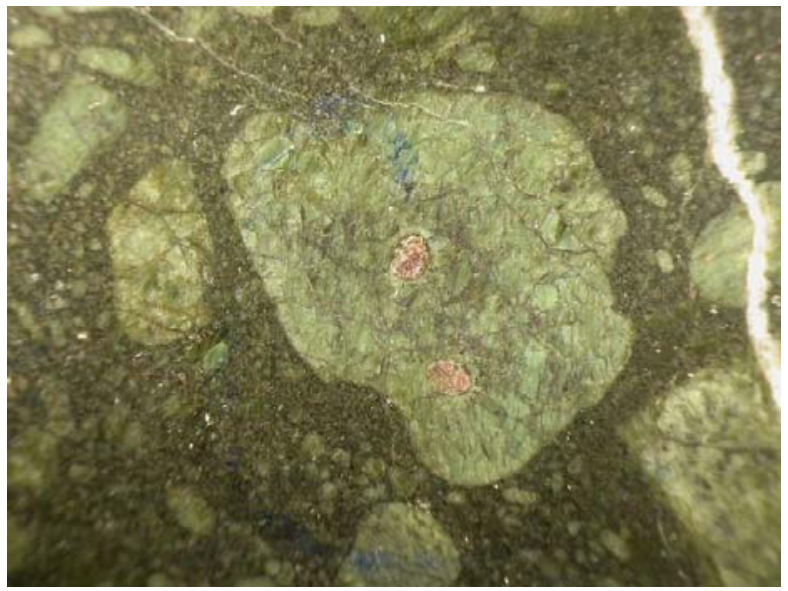

Fig. 2. Macrocrystic HK (197m depth, central part of the pipe), olivine phenocrysts and an olivine macrocryst including $1 \mathrm{~mm}$ garnets are set in a fine crystallized groundmass; FOV 22mm.

We use the term coherent magma particles (CMP) for rounded-subrounded, sometimes irregular to amoeboid shaped coherent clasts with a macrocrystic or aphyric texture. CMP could be juvenile, accessory, or recycled pyroclasts (or cognate lithics - represented by rare angular and/or abraded broken re-incorporated fragments), however distinguishing their true origin is rarely possible. At least some of the CMP are the product of magma disruption in a semi-plastic state or even of welded material, as indicated by their fluidal outline and internal grain-aligned texture. At least some of the CMP may also be part of a complex 
peperite system that intrudes the base of the pipe. Sometimes cm-sized spherical CMPs (cored or uncored particles, 3 - $15 \mathrm{~mm}$ in diameter with a dense microporphyritic rim of tangentially-oriented crystals; they indicate spinning and recapturing of particles due to surface tension) are present, hosted within fragmental kimberlite autoliths and larger coherent magmatic particles (Figs 4 and 5).

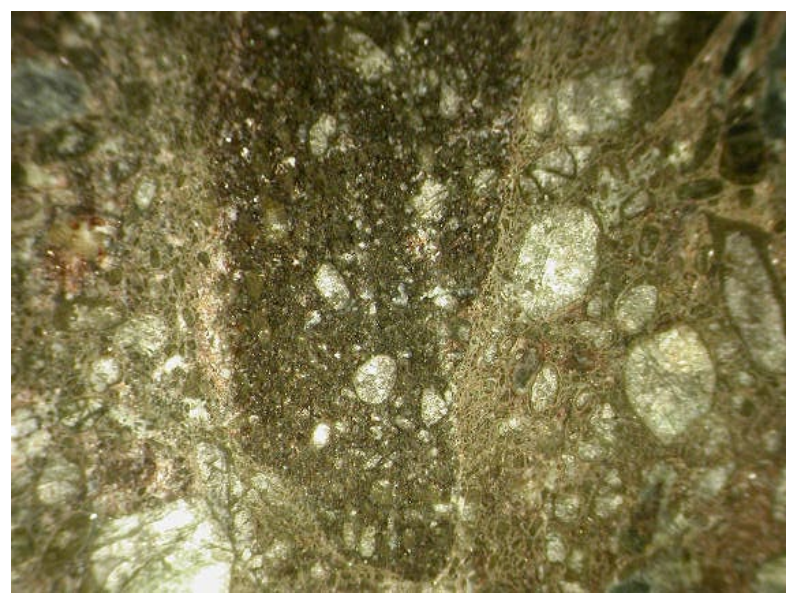

Fig. 3. Inhomogeneous texture of HKt (280m depth SE part of pipe) showing a CMP set in an interstitial phase of similar composition, FOV 20mm.

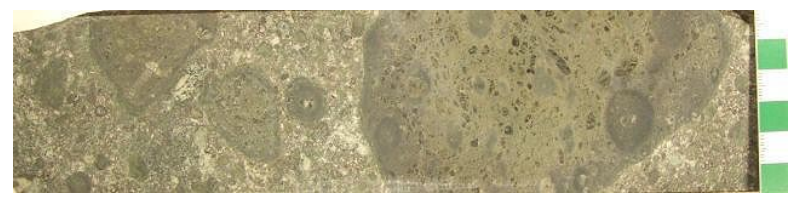

Fig. 4. Spherical CMPs within a larger CMP and within a transitional TK matrix, slab photo (177.55-178.11m depth, SW part of the pipe).

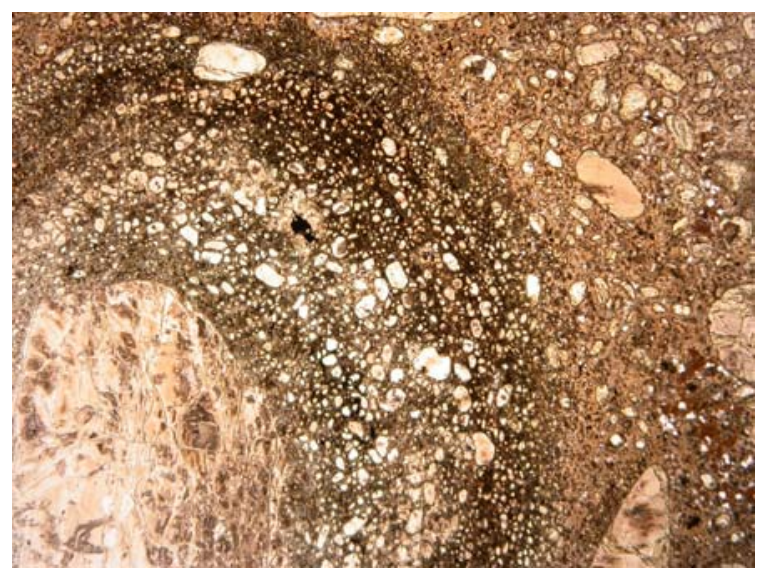

Fig. 5. Detail of a spherical juvenile CMP of Fig. 4, showing fine, tangentially oriented olivine phenocrysts around an olivine macrocryst core, included in a larger CMP; FOV-15mm.

Steeply bedded epiclastic grain flow deposits (ED) occur in deep levels of the pipe and especially under the downwards widening roof segments (Fig. 6). The gradual contact relationships of these deposits with the surrounding kimberlite rocks as well as their location suggest an in situ origin.

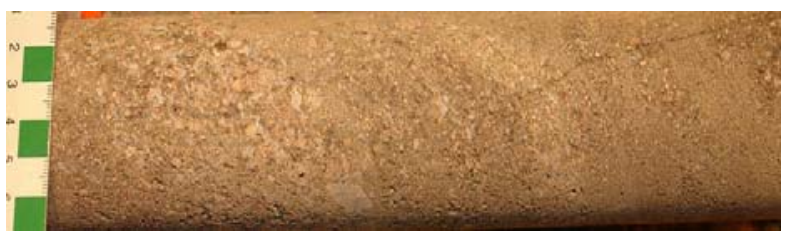

Fig. 6. Steeply bedded fine to medium-grained epiclastic sequence rich in granitic material, suggesting grain flow type deposition (355m depth, SW part of the pipe).

Within and in between the kimberlite facies a variable and often high abundance of local country rock xenoliths is observed, varying in size from sub-mm to several tens of meters. Country rock fragments can be found in any location within the pipe, but are especially common in a belt-like area at a depth of 120-200 m and under the widening roof. Based on the texture, structure and composition of the breccias, we interpret these breccias as contact breccias (partly with jigsaw fit textures), grain flows (Fig. 6), pyroclastic deposits, slumped debris, subsided floating reefs, and rock falls (Fig. 7) as well as heterogeneous mixed breccias resulting from recycling processes ( Fig 8).

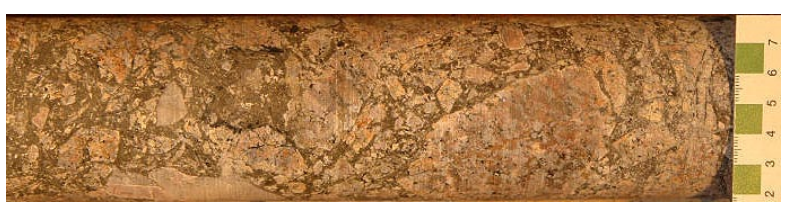

Fig. 7. Granite breccia (174 m central part of the pipe). Note the angular fragments (with occasional rounding of smaller particles), differentially rotated with respect to each other, and jointly enclosed voids filled with very fine fragmented particles; breccia formed by rock fall processes within the pipe under the overhanging granite roof.

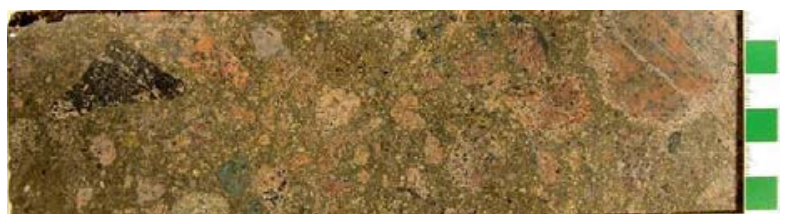

Fig. 8. Heterogeneous angular, subround and variously altered country rock xenoliths in transitional TK $(257 \mathrm{~m}$ center of the pipe).

The shape and facies architecture in Tuzo pipe indicate a root zone-diatreme transitional structural level. Heterogeneous breccias, composite CMPs and lithofacies with different textures and composition directly juxtaposed (Fig. 9) imply that recycling processes were active over time. In situ grain flows, rock fall breccias and softly-deformed clasts of welded kimberlite point towards the presence of temporary caves in the root zone. 


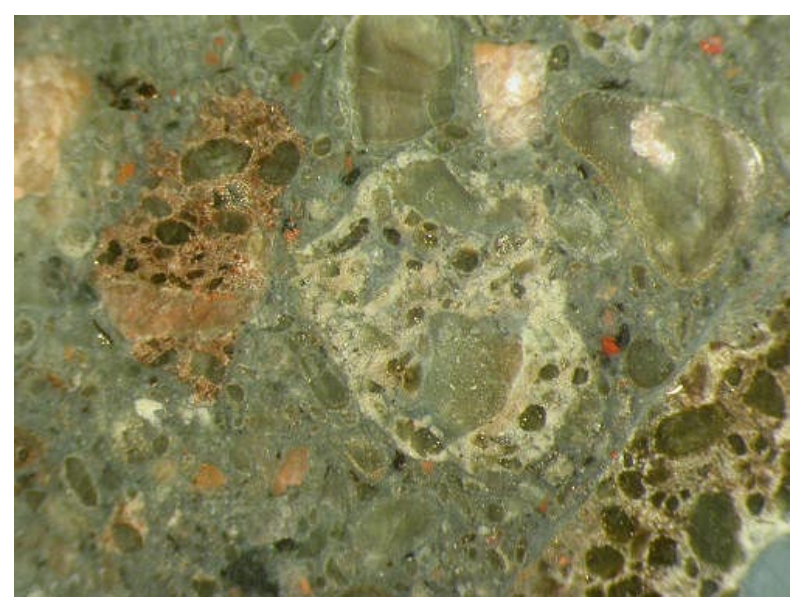

Fig. 9. Transitional TK in binocular (202m depth, central part of pipe), note that CMP particles have different groundmass composition and olivine phenocryst sizes, which suggests recycling processes, FOV $22 \mathrm{~mm}$.

Our simplified 3D geological model (Fig. 10a) separates several units: TK, an upper transitional TKt as two distinct units, (TKt1_1 and TKt1_2 based on the depth of occurrence, association with other facies within the pipe and degree of dilution) and a lower TKt2. HKt is combined with TKt as a distinctive model unit HKt+TKt. HK is incorporated in all the other model units, mostly in TKt2 or HKt+TKt model units. Only the thick basal section of epiclastic deposits (ED) was modeled separately, while the thinner ED units in the upper central part of the pipe were grouped together with the incorporating dominant kimberlite facies. The TKt2 breccia of Tuzo pipe (Fig. 3) is the most well preserved zone representing the transition from the root zone into a diatreme above. The largest granite block (the only one modeled separately in the 3D model of Fig. 10b) is encountered between $300-350 \mathrm{~m}$ depth in 5 cores in the central western part of the pipe.

It is clear from our study that the emplacement of Tuzo pipe did not occur in a single, violent explosion, but that repeated phases of volcanic explosions alternated with periods of relative quiescence. The observed volcanological features are typical of those expected in the thermohydraulic process chain (e.g. Lorenz and Kurszlaukis, 2007), which may include phases of less explosive magmatic activity.

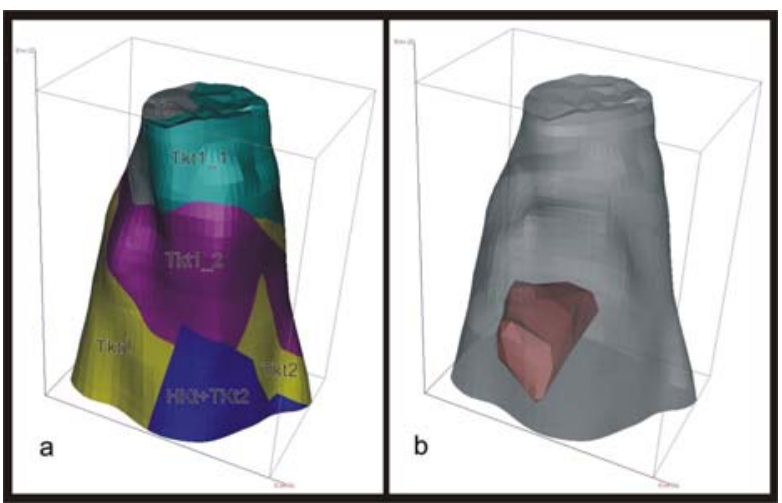

Fig. 10. Side views looking south (a) three-dimensional simplified geological model of the Tuzo pipe and (b) semi-transparent hull showing the granite block as shaded area

In detail, the pipe is suggested to form by a downward migration of explosive activity. Initial highly explosive eruptive phases fragment magma and country rock, and vigorously expel the material upward into the overlying pile of loose debris filling the diatreme. It results in the disruption of earlier deposits including the country rock breccias, and mixing of the various materials. During the waning stage of an eruptive phase and favored by temporarily created underground open cavities in the excavated explosion chamber, late volcanic fragmentation generated spherical juvenile particles and rapidly accumulated and agglutinated hot pyroclastic material (HKt), probably formed by less energetic magmatic eruptions. In addition, epiclastic grain flow deposits are emplaced by sporadic resedimentation events under the flaring roof of the pipe. Intrusion of $\mathrm{HK}$ dikes and sheets into the fragmental and transitional kimberlites follows and creates the complex intrusive network of a peperite.

To conclude, the emplacement of Tuzo pipe was a process extended over a period of time with repeated eruptions of variable magnitude and nature. Resedimentation and recycling of volcaniclastic material is evident.

\section{References}

Hetman, C.M., Scott-Smith, B.H., Paul, J.L. and Winter, F., 2004. Geology of the Gahcho Kué kimberlite pipes, NWT, Canada: root to diatreme magmatic transition zone. Lithos 76, 51-74.

Lorenz, V. and Kurszlaukis, S., 2007. Root zone processes in the phreatomagmatic pipe emplacement model and consequences for the evolution of maar-diatreme volcanoes. Journal of Volcanology and Geothermal Research, 159: 4-32. 